\title{
The Technology and Application of the Tree Planting Baseplate in Bare Rock Area
}

\author{
Xiaohan Zhou, Hongkai Chen, Hongmei Tang \\ Institute of Geotechnical Engineering, Chongqing Jiaotong University, Chongqing, China \\ Email: 897293490@qq.com
}

How to cite this paper: Zhou, X.H., Chen, H.K. and Tang, H.M. (2016) The Technology and Application of the Tree Planting Baseplate in Bare Rock Area. World Journal of Engineering and Technology, 4, 1-7. http://dx.doi.org/10.4236/wjet.2016.43C001

Received: April 28, 2016

Accepted: September 19, 2016

Published: September 22, 2016

\begin{abstract}
The ecological greening technology of the bare rock area of the arbor governance belongs to the field of ecological environment restoration, selection of suitable arbors for vegetation restoration in bare rock area, vegetation recovery is the primary approach to governance the ecological environment of bare rock area. The reconstruction of bare rock area arbor-shrub-grass ecosystems is a global environmental science problem. Paying attention to Geological conditions with rich rock fissures and abundant groundwater in these fissures, following the idea to reconstruct ecosystem from arbor to shrub and grass and the principle one tree in a baseplate, authors develop a baseplate technique for tree planting in bare rock area. The baseplate includes the parent body, the root, and the cover to prevent evaporation. Especially, there are filled in nutritional soil for the parent body and the root, and the composition of nutritional soil are selected by test in laboratory, while optimal mix ratio of the composition is obtained. Then, application method in field is put forward. The technique can guarantee survival at early stage and growth in the later for tree planting in the baseplate. In particular, the root provides a good channel to guide tree roots into fissure rock and absorb groundwater in rock. Test in field shows that the baseplate technique has strong practicality in vegetation recovery of bare rock area. Test in field shows that the baseplate technique has strong practicality in vegetation recovery of bare rock area in the world.
\end{abstract}

\section{Keywords}

Bare Rock Area, Tree Planting, The Baseplate Technique, Test in Field

\section{Introduction}

The vegetation restoration of bare rock area is one of the difficult problems in the engineering field. Due to the exposed rock, there are high mountains and steep slopes, 
human activities severely damaged vegetation, serious soil erosion, and the large area of bedrock exposed causing land degradation. Rocky desertification is the main cause of the rock exposed, China is the most serious country in the world, by the end of 2011, the total area of rocky desertification is $12.2 \times 105 \mathrm{~km}^{2}$, mainly in Guizhou, Guangxi, Sichuan, Chongqing, Yunnan, Hubei, Hunan, Guangdong etc (cities, districts) of 455 counties in 5575 townships, one of the largest area of rocky desertification is Guizhou Province, $3.024 \times 104 \mathrm{~km}^{2}$, followed by Yunnan Province, rocky desertification area of $2.84 \times 104 \mathrm{~km}^{2}$ [1]. The natural factors that causing rocky desertification are numerous, the slow process of carbonate rock formation and high frequency extreme heavy rainfall is easy to produce soil and water loss. And human activities, such as excessive deforestation, excessive land reclamation, over grazing, large-scale road and urban infrastructure construction, Chinese Academy of Sciences, respectively submit a report to the State Council, proposed to promote the southwest Karst area of the comprehensive management of rocky desertification two times in 1994 and 2003 [2] [3]. So it can be seen that the effective treatment of rocky desertification is a hot issue in the prevention of rocky desertification at home and abroad. Foreign scholars pay more attention to the study of vegetation growth conditions in rocky desertification area, the prediction model of surface runoff in karst area was proposed by Majone et al. [4] Ries et al. [5] studied the regional migration characteristics of soil moisture in the semi arid region of Karst; Chen Hongkai et al. proposed a growth base technique for vegetation growth in grey rocky desertification area. The practice shows that the vegetation restoration method of the arbor-shrub-grass in the limestone area is the primary approach to govern the bare rock, the planting survival and sustainable growth of the arbors species are the point. This paper aimed at the problem of the tree planting in the bare rock area, the development of new technology based on the geological conditions of the extreme development of the limestone in the bare rock area and the easy occurrence of groundwater in the fracture, the research results have positive significance for effectively solving the problem of the internationalization of the tree planting in the bare rock area.

\section{The Research and Development of the Tree Planting Baseplate in the Bare Rock Area}

He Xiang et al. [7] in the management of rocky desertification in Guizhou Hua Jiang Gorge, the artificial blasting is put forward and the soil is placed in the pit, growing plants in the soil and ensuring the growth of plants by irrigation and drip irrigation. But in rocky desertification area, rock is exposed, the soil is poor, the temperature difference between day and night is big, the effect of the existing tree planting program is not good. This study follows the principle of "making full use of limestone fissure water" and "a base plate of a tree" to ensure the survival and sustainable growth of the trees in the bare rock area, authors develop a baseplate technique for tree planting in bare rock area [6] [8], the baseplate includes the parent body, the root, and the cover to prevent evaporation (Figure 1, Figure 2), the base matrix and drain wet root filled with water nutrient soil, the composition and optimization with the soil as shown in Table 1. 


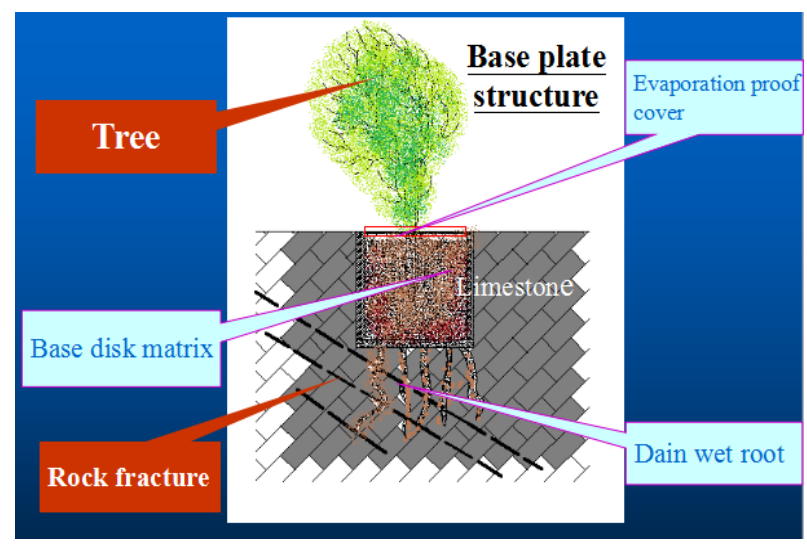

Figure 1. The structure of the base plate in bare rock region.

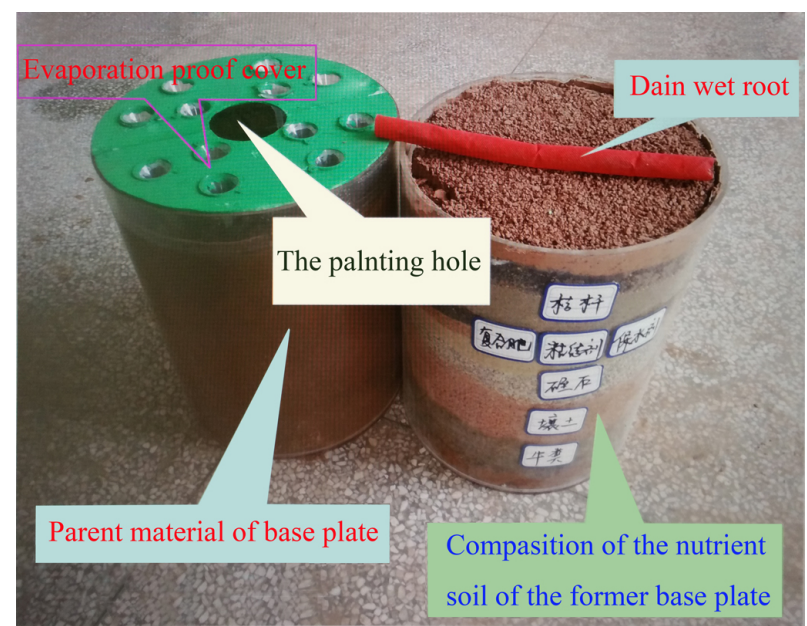

Figure 2. The real object of baseplate for tree planting.

Table 1. Composition of nutritional soil in baseplate.

\begin{tabular}{ccc}
\hline Composition & Proportion (\%) & Major function \\
\hline The fermentation of cow dung & 40.0 & Organic fertilizer \\
Loam & 32.2 & Soil grain structure \\
Straw powder & 20.0 & Regulating soil pore \\
Vermiculite & 6.0 & Fertilizer and air permeability \\
Compound fertilizer & 0.7 & Nitrogen, phosphorus, potassium \\
and other growth elements \\
Water retaining agent & 0.6 & Keep water \\
Binder & 0.5 & Soil adhesion \\
\hline
\end{tabular}

The substrate can solve the problem of lacking of nutrients and water in the initial stage of the plant, and is in the shape of a cylinder, diameter $23-28 \mathrm{~cm}$, high $25-30$ $\mathrm{cm}$, hole diameter $5-10 \mathrm{~cm}$, hole depth $10-15 \mathrm{~cm}$; Drain wet root is the core of the technology, the outside package of geotextiles, $1-1.5 \mathrm{~cm}$ in diameter, length $30 \mathrm{~cm}$, in- 
stall in the base plate at the bottom of the deep rock body, the absorption of groundwater and nutrients in the fracture of rock mass can be obtained, and tree saplings root deeply fissured rock provided the main channel; Anti evaporation cover is provided for the water seepage holes, micro funnel collector, top aperture $0.5-1 \mathrm{~cm}$, bottom aperture $0.1-0.3 \mathrm{~cm}$, water seepage holes can collect rainfall through the funnel-shaped catchment is transported to the tree planting base, in order to make the base matrix reduce evaporation and easy to absorb atmospheric precipitation.

The application effect of this technique is shown in Figure 3, through the first to achieve the restoration of trees, to protect the natural growth of shrubs and herbs, and to achieve the bare rock area ecosystem reconstruction. From the component composition of baseplate, nutrient soil, baseplate pit excavation artificial cost, each baseplate cost is about 60 yuan.

\section{Test in Field}

After a large number of testing in Geleshan and Nanshan of Chongqing, the area is Nanshan Valley anticline, nearly horizontal strata occurrence, the area is Triassic Jialingjiang formation and Leikoupo Formation of limestone karst landforms, bare rock, no perennial vegetation growth, an area of about 500 square meters. In the test site dug 8 baseplate pit, the pit diameter of about $20 \mathrm{~cm}$, the depth of about $50 \mathrm{~cm}$. In the base of the bottom of the hole with drill air gun drill set 5 - 8 root hole, hole depth $50-80 \mathrm{~cm}$

(Figure 4). Baseplate pit is used for placing the vegetation growth baseplate, the toot provides a good channel to guide tree roots of baseplate into fissure rock.

When the baseplate pit excavation is completed, baseplate for field installation procedure: wall with mud-place the prepared drain wet root in the wet root hole-place the baseplate in the baseplate pit-place the seedlings in the middle of the base plate and make them stand upright-on the base surface of the base plate, the evaporation cover is arranged.

In February 1, 2015, a total of 8 trees were planted in the experimental site, The seedlings were planted and had never been watered and fertilized, from April 20, 2015

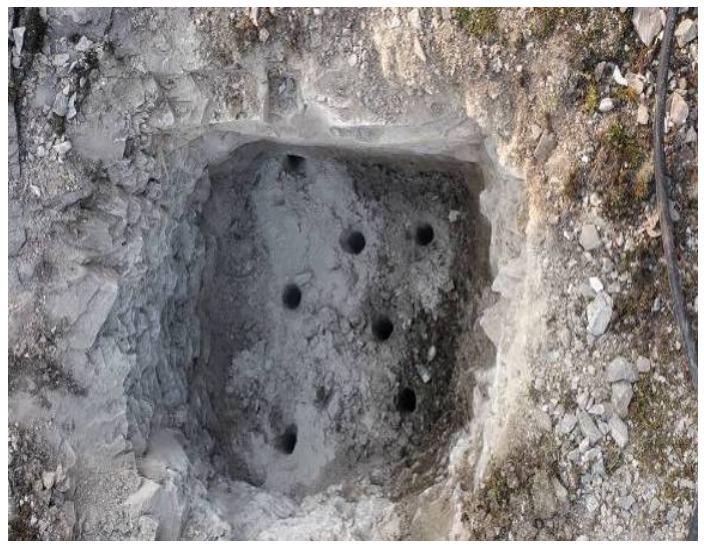

Figure 3. The application working sketch of baseplate technique in bare rock area. 
onwards, continuous tracking observation of the growth status of planted trees. According to the Chongqing Municipal Meteorological Bureau report, in 2015 the main city and the surrounding area has severe weather, test area in 7 - 8 months without rain for 42 days, but the planted trees have survived and are growing well (Figure 5, Figure 6). It is worth pointing out that after trees grow new shoots, some buds were eat by goats, such as $6 \#$ and $8 \#$, this is a warning to people that during the period of vegetation restoration of bare rock area, it should be prohibited to enter the fieleto protect the early growth of trees.

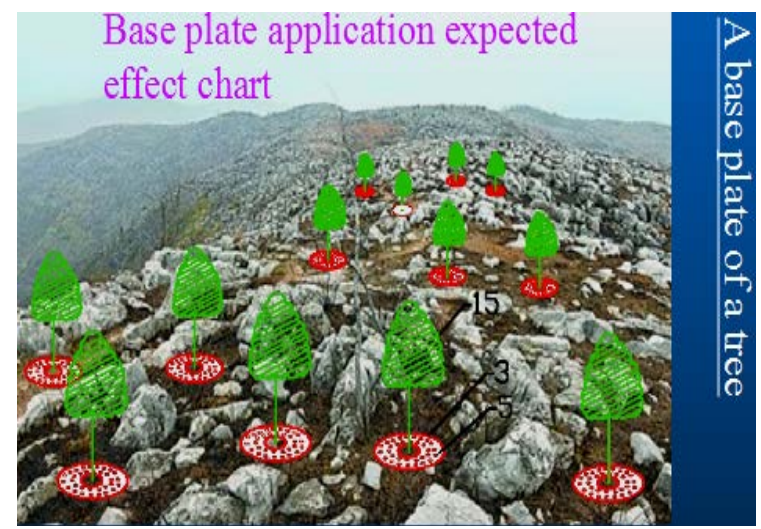

Figure 4. A root base bottom hole drilling.

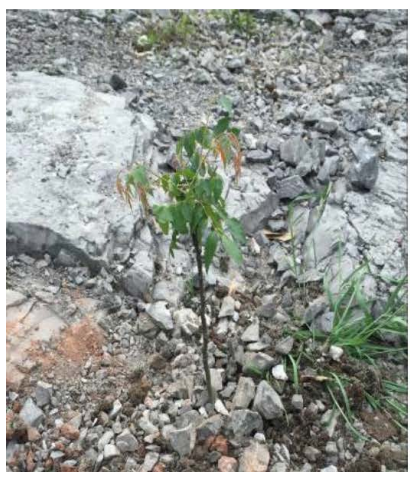

April 20th: trees survive

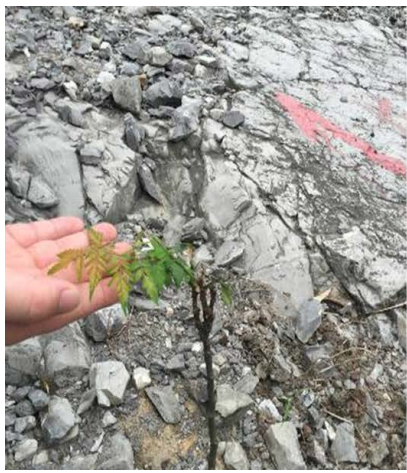

June 23rd: bud length $14 \mathrm{~cm}$

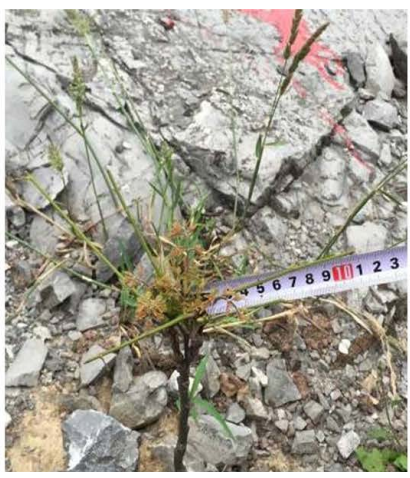

May 5th: bud length $2.3 \mathrm{~cm}$

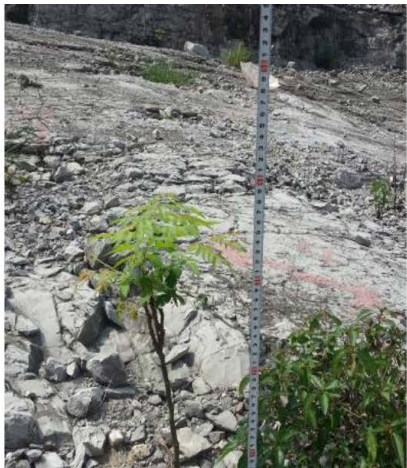

August 22nd: bud length $15 \mathrm{~cm}$

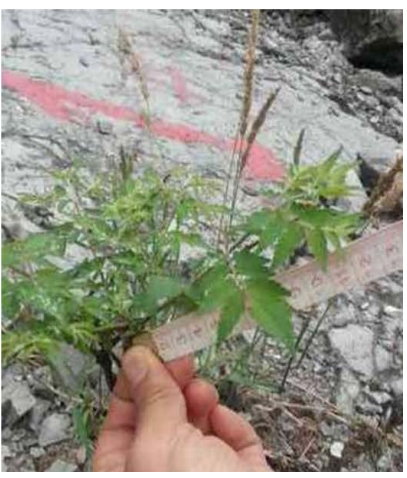

May 20th: bud length $12 \mathrm{~cm}$

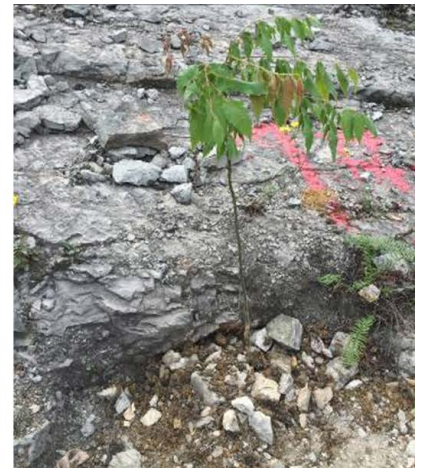

October 1st: bud length $15.7 \mathrm{~cm}$

Figure 5. Observation results of $1 \#$ trees. 


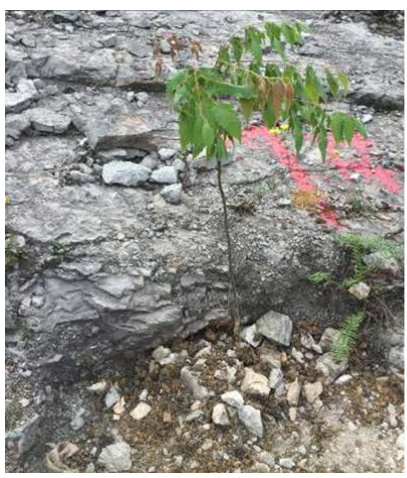

April 20th: trees survive

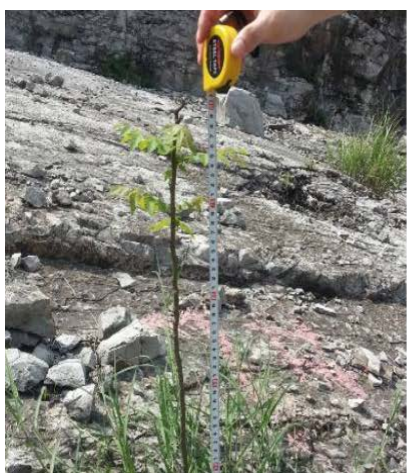

August 22nd: bud length $16 \mathrm{~cm}$

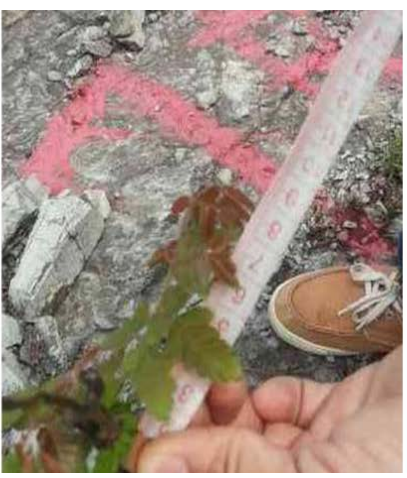

May 20th: bud length $8.9 \mathrm{~cm}$

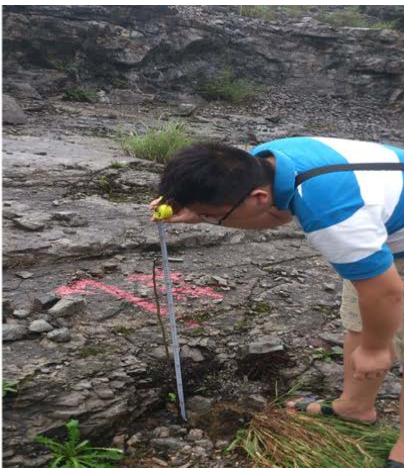

September 16th: the top shoots the sheep eats, shoots regeneration $2 \mathrm{~cm}$

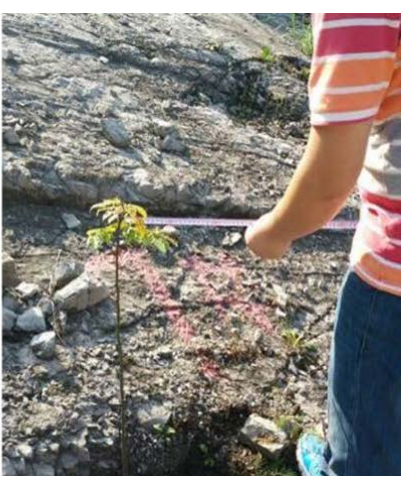

June 9th: bud length $13.2 \mathrm{~cm}$

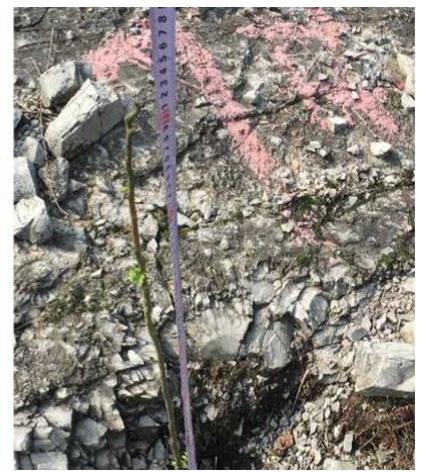

October 1st: regeneration bud length $7 \mathrm{~cm}$

Figure 6. Observation results of $7 \#$ trees.

\section{Conclusions}

In the face of exposed rock area, the soil and water loss is serious, the rock is exposed, and the lack of soil is short of water, it is not conductive to the restoration of vegetation, especially the objective reality of the survival and sustainable growth of tree species. This study focuses on the development of rock mass fracture in limestone area and the abundant geological environment conditions in the groundwater, the problem of planting trees in the bare rock area was studied, and the following results were obtained:

1) Following the idea to reconstruct ecosystem from arbor to shrub and grass in bare rock area, focusing on the planting of arbor species, and put forward the principle of "a baseplate of a tree", the author developed a tree planting baseplate technique, it includes the development of baseplate and the process of field applications.

2) The baseplate technique includes the parent body, the root, and the cover to prevent evaporation, there are filled in nutritional soil for the parent body and the root, and the composition of nutritional soil are selected while optimal mix ratio of the composition is obtained.

3) Field application of arbor planting baseplate following the procedure of "digging baseplate pit-wall with mud-placed the prepared drain root wet in the hole-position the baseplate in the baseplate pit-placing the seedlings in the middle of the base plate and 
make them stand upright-putting the evaporation proof cover into the surface of the parent baseplate".

4) From February to October of 2015, the field test results showed that this technique can ensure the survival and sustainable growth of the tree species in the bare rock area. If it can be applied in the bare rock area, we can take the lead in the reconstruction of bare rock area of arbor - shrub - grass ecosystem in arbor vegetation, This provides the necessary growth conditions for the late recovery of shrubs and herbaceous vegetation.

\section{References}

[1] The State Forestry Administration of the People's Republic of China. The Bulletin of Rocky Desertification Situation in China. The State Forestry Administration of the People's Republic of China, Beijing, 2012.

[2] The Earth Division of Chinese Academy of Science (1994) A Proposal Concerning Sustainable Development in the Karst Stony Mountain Area in Southwestern China. Bulletin of the Chinese Academy of Sciences, No. 4, 343-345.

[3] The Earth Division of Chinese Academy of Science (2003) Suggestions on the Promotion of the Comprehensive Management of Rocky Desertification in Southwest China's Karst Region. Bulletin of the Chinese Academy of Sciences, No. 3, 169.

[4] Majone, B., Bellin, A. and Borsato, A. (2004) Runoff Generation in Karst Catchments: Multifractal Analysis. Journal of Hydrology, 294, 176-195.

[5] Ries, F., Lange, J., Schmidt, S., et al. (2015) Recharge Estimation and Soil Moisture Dynamics in a Mediterranean, Semi-Arid Karst Region. Hydrology Earth System Science, 19, 14391456.

[6] Chen, H.K., Wu, F. and Tang, H.M. (2014) Methods of Manufacture and Cultivating the Plant-Base in the Limestone Rocky Desertification Areas: China. 201410706842.9. 2014-1127.

[7] He, X., Xiong, K.N., Li, C., et al. (2011) Study on Soil Quality Effect in Ecological Management of Rocky Desertification in Karst Mountainous Area: A Case Study of Huajiang Canon Demonstration Area of Guizhou Province. Guizhou Agricultural Sciences, 39, 99-102.

[8] Zhou, X.H., Chen, X.N., Qin, X., et al. (2015) Plant-Base for Trees in Rocky Desertification Areas: China. 201520222119,3. 2015-04-14.

\section{Submit or recommend next manuscript to SCIRP and we will provide best service for you:}

Accepting pre-submission inquiries through Email, Facebook, LinkedIn, Twitter, etc.

A wide selection of journals (inclusive of 9 subjects, more than 200 journals)

Providing 24-hour high-quality service

User-friendly online submission system

Fair and swift peer-review system

Efficient typesetting and proofreading procedure

Display of the result of downloads and visits, as well as the number of cited articles

Maximum dissemination of your research work

Submit your manuscript at: http://papersubmission.scirp.org/ 